\title{
Influence of Temperature on Typical Texture Distribution in Primary Recrystallization Matrix of 3\% Si CGO Silicon Steel
}

\author{
Zhi-chao Li, ${ }^{1}$ Ning Dang, ${ }^{2}$ and Zhen-li $\mathrm{Mi}^{2}$ \\ ${ }^{1}$ Collaborative Innovation Center of Steel Technology, University of Science and Technology Beijing, Beijing 100083, China \\ ${ }^{2}$ Institute of Engineering Technology, University of Science and Technology Beijing, Beijing 100083, China \\ Correspondence should be addressed to Zhi-chao Li; lizhichao1225@163.com
}

Received 1 April 2016; Revised 6 June 2016; Accepted 8 June 2016

Academic Editor: Zhengyi Jiang

Copyright (c) 2016 Zhi-chao Li et al. This is an open access article distributed under the Creative Commons Attribution License, which permits unrestricted use, distribution, and reproduction in any medium, provided the original work is properly cited.

\begin{abstract}
OM (optical microscopy) and EBSD (electron backscatter diffraction) techniques were used to study microstructure and texture distribution during primary recrystallization under different intermediate annealing temperatures in CGO silicon steels. The effect of intermediate annealing temperature on texture distribution in $3 \% \mathrm{Si}$ electrical steel was analyzed. The results indicate that the microstructure in primary recrystallization matrix of CGO silicon steel is comprised of equiaxed ferrite grains. Mean grain size of primary recrystallization increases with the rising of intermediate annealing temperature. $\gamma$-fiber texture is the dominant component in primary recrystallization matrix. With higher intermediate annealing temperature, $\{111\}\langle 121\rangle$ texture and $\{111\}\langle 110\rangle$ texture increase and $\{111\}\langle 121\rangle$ texture is stronger than $\{111\}\langle 110\rangle$ texture. Goss texture was observed to be decreased firstly and then increased. The content of high angle grain boundaries in primary recrystallization matrix are affected by intermediate annealing temperature. When intermediate annealing temperature is increased, high angle grain boundaries are increased firstly and then decreased. Misorientation distribution in primary recrystallized matrix is affected by primary recrystallization annealing temperature either. The content of high angle grain boundaries are increased owing to higher primary recrystallization annealing temperature, which can be a benefit to the abnormal growth of Goss grains in secondary recrystallization.
\end{abstract}

\section{Introduction}

Grain-oriented silicon steel is mainly used as the core material of large transformer, motor, and ballast devices; the manufacturing technology and product quality of silicon steel plate are important symbols for the development of special steel production and technology of a country. Grain-oriented silicon steel is divided into conventional grain-oriented silicon steel (CGO) and high magnetic induction grain-oriented silicon steel (Hi-B) by the average deviation angle of Goss grains $\{100\}\langle 001\rangle$ and magnetic properties. CGO silicon steel and Hi-B silicon steel also have some differences in the production process: Hi-B steel uses single-stage cold rolling process; CGO silicon steel uses two-stage cold rolling process and added intermediate annealing treatment between the two-stage cold rolling process. A large number of studies have been made on the microstructure, texture, and inhibitors of hot rolled plate and normalizing and cold rolled plate of
CGO silicon steel during the manufacturing process so far; however, the study of the influence of intermediate annealing temperature on the microstructure and texture in primary recrystallization matrix is not sufficient, and the intermediate annealing has a great influence on the formation of final texture of CGO silicon steel and the optimization of magnetic properties. The effect of intermediate annealing temperature on the microstructure and properties of $2.3 \%$ Si electrical steel has been studied by Miao et al. [1], who found that higher intermediate annealing temperature makes the microstructure become coarse before secondary cold rolling, which is a benefit to acquire Goss texture during recrystallization annealing. The effect of intermediate annealing process on microstructure and texture has been studied by Ju et al. [2], who found that the intermediate annealing temperature has little effect on the texture component after decarburization annealing; however, the higher intermediate annealing temperature will lead to the increase of Goss texture density after 
secondary recrystallization. The effect of rolling reduction and intermediate annealing on microstructure and texture of $6.5 \%$ Si high silicon steel has been studied by Liu et al. [3]. The effect of intermediate annealing process on the performance optimization of CGO silicon steel has been studied by Chen et al. [4], who found that the orientation and content of Goss texture can be effectively optimized by adjusting the temperature and time of intermediate annealing. The influence of intermediate annealing temperature on the typical textures in primary recrystallization matrix of 3\% Si CGO silicon steel has been studied, and the formation regularity of important texture components has been analyzed, provided reference for the texture control of practical production exists.

\section{Experimental}

2.1. Materials. The fabrication of CGO silicon steel billet was prepared by vacuum induction smelting furnace, which has main components (wt\%) of $2.95 \% \mathrm{Si}, 0.095 \% \mathrm{C}, 0.15 \% \mathrm{Mn}$, and $0.027 \% \mathrm{~S}$.

2.2. Specimen Processing. The ingot was forged to $30 \mathrm{~mm} \times$ $100 \mathrm{~mm} \times 120 \mathrm{~mm}$ at $1150^{\circ} \mathrm{C}$ and then rolled to a thickness of $2.3 \mathrm{~mm}$ by five passes rolling at $1360^{\circ} \mathrm{C}$. After that, the plate was cold rolled to a thickness of $0.68 \mathrm{~mm}$ and finally secondary cold rolled to a thickness of $0.27 \mathrm{~mm}$ after intermediate annealing; then, the primary recrystallization annealing was performed. Intermediate annealing was needed after the first cold rolling in order to make the two-stage rolling smooth, and the content of Goss grains could be enhanced through recovery and recrystallization. Three temperatures of intermediate annealing, which, respectively, are $800^{\circ} \mathrm{C}$, $840^{\circ} \mathrm{C}$, and $860^{\circ} \mathrm{C}$, were selected. The cold rolled plates were held for $600 \mathrm{~s}$ in an annealing furnace which had an atmosphere mixed of $\mathrm{N}_{2}$ and $\mathrm{H}_{2}(3: 1)$. The mixed gas was transited in a $60^{\circ} \mathrm{C}$ water bath before entering into the annealing furnace. During intermediate annealing, the plate was rapidly decarburized by water vapor in weak oxidizing atmosphere of the furnace. C content of these plates was therefore reduced to $30 \mathrm{ppm} \pm 2 \mathrm{ppm}$ after intermediate annealing. Decarburization annealing is taken to reduce the carbon content and to complete the primary recrystallization in order to generate sufficient amount of $\{110\}\langle 001\rangle$ oriented grains in the matrix, which is also conducive to grain growth. The temperatures of primary recrystallization annealing were $820^{\circ} \mathrm{C}$ and $850^{\circ} \mathrm{C}$, respectively; the experimental plates were held for $240 \mathrm{~s}$ in an atmosphere mixture of $\mathrm{N}_{2}$ and $\mathrm{H}_{2}$ with a ratio of $3: 1$. If a plate was underwent intermediate annealing at $800^{\circ} \mathrm{C}$ and primary recrystallization annealing at $850^{\circ} \mathrm{C}$, its process was indicated as $800^{\circ} \mathrm{C}+850^{\circ} \mathrm{C}$ as shown in Table 1 .

2.3. Test Methods. The microstructures of specimens were observed along the longitudinal section of the $\mathrm{RD}$ direction using optical microscopy (OM). The texture distribution was measured by electron backscatter diffraction (EBSD) attached to SUPRA ZEISS 55 scanning electron microscope (SEM).
TABLE 1: Heat treatment schedule.

\begin{tabular}{lcc}
\hline Representation & $\begin{array}{c}\text { Intermediate annealing } \\
\text { temperature } /{ }^{\circ} \mathrm{C}\end{array}$ & $\begin{array}{c}\text { Primary recrystallization } \\
\text { temperature } /{ }^{\circ} \mathrm{C}\end{array}$ \\
\hline $800^{\circ} \mathrm{C}+820^{\circ} \mathrm{C}$ & 800 & 820 \\
$840^{\circ} \mathrm{C}+820^{\circ} \mathrm{C}$ & 840 & 820 \\
$860^{\circ} \mathrm{C}+820^{\circ} \mathrm{C}$ & 860 & 820 \\
$800^{\circ} \mathrm{C}+850^{\circ} \mathrm{C}$ & 800 & 850 \\
$840^{\circ} \mathrm{C}+850^{\circ} \mathrm{C}$ & 840 & 850 \\
$860^{\circ} \mathrm{C}+850^{\circ} \mathrm{C}$ & 860 & 850 \\
\hline
\end{tabular}

\section{Results and Discussion}

3.1. Microstructures Analysis after Primary Recrystallization. Figures 1(a)-1(f) illustrate the microstructures of specimens that experienced different annealing processes. As shown in Figure 1, the average grain size of CGO silicon steel after primary recrystallization increases with the rising of intermediate annealing temperature. Recrystallization is a process which included nucleation and growth; the driving force of recrystallization is the difference in the distortion energy between the grains. The main resistance of recrystallization is the boundary energy. When the annealing temperature increases, the nucleation generates at the original high angle grain boundaries or the high angle subboundaries which are formed through the growth of the subgrain. In general concepts, the boundaries whose misorientations are less than $10^{\circ}$ belong to the low angle grain boundaries [5], and those whose misorientations are greater than $15^{\circ}$ belong to the high angle grain boundaries. After recrystallization, grains can grow up continually owing to the movement of grain boundaries and the combination of grains. The annealing temperature is an important factor to influence the recrystallization. The relationship between diffusion coefficient $(D)$ and activity of the grain boundary $(B)$ is given in (1), and the relationship between $D$ and temperature (T) is given in (2) [6]:

$$
\begin{aligned}
B & =\frac{D}{k T}, \\
D & =D_{0} \exp \left(-\frac{Q}{k T}\right),
\end{aligned}
$$

where $B$ is the activity of the grain boundary, $D$ is the diffusion coefficient, $k$ is the Boltzmann constant, $T$ is the absolute temperature, $D_{0}$ is the diffusion constant, and $Q$ is the diffusion activation energy. From (1) and (2) it can be seen that although there is an inversely proportional relationship between $B$ and $T$, the grain boundary diffusion coefficient $D$ and temperature $T$ are exponentially positively correlated, the effect of $D$ on $B$ is significantly greater than that of $1 / T$. Therefore, the grain boundary activity is greatly affected by temperature. The migration rate of grain boundaries increases with the rising of annealing temperature; in the same annealing time, the higher the temperature, the greater the possibility of grain growth. The grain size has significant effect on the texture and magnetic properties of grain-oriented silicon steel, and the grain size uniformity is also improved with increasing annealing temperature. 


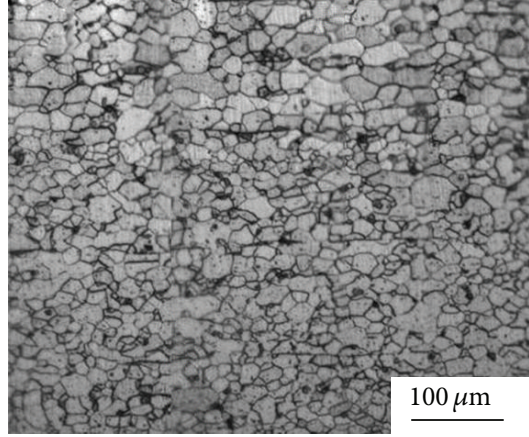

(a)

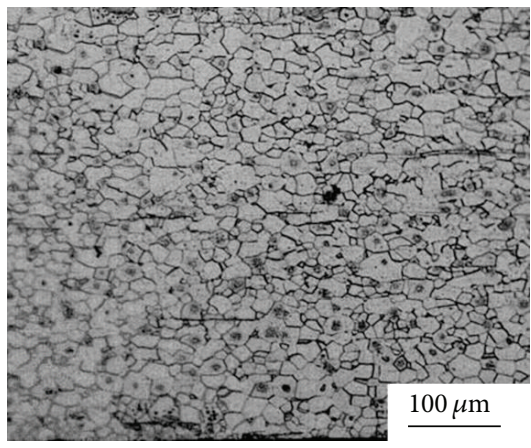

(d)

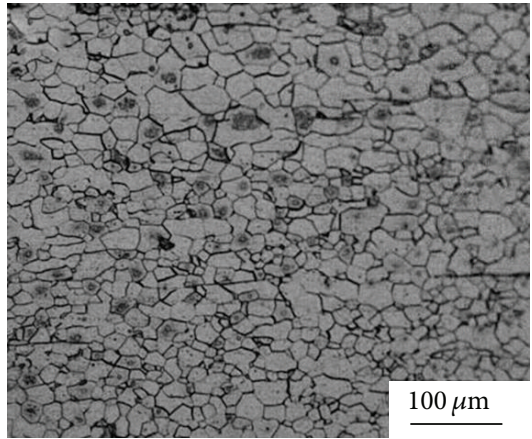

(b)

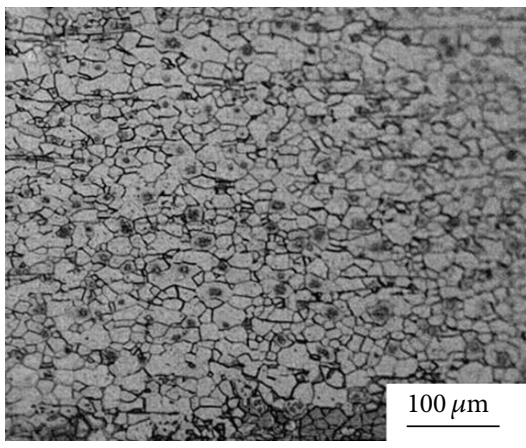

(e)

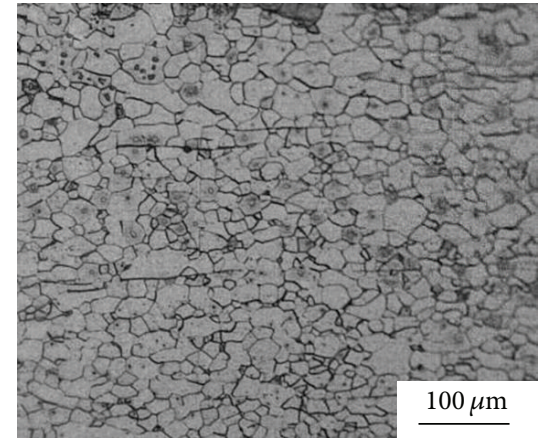

(c)

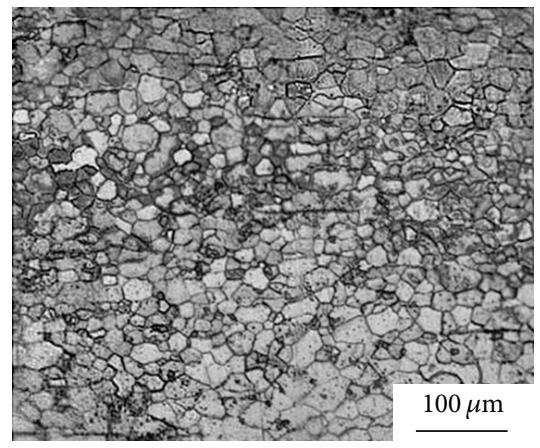

(f)

Figure 1: Microstructures of tested samples under different intermediate temperatures during primary recrystallization: (a) $800^{\circ} \mathrm{C}+850^{\circ} \mathrm{C}$; (b) $840^{\circ} \mathrm{C}+850^{\circ} \mathrm{C}$; (c) $860^{\circ} \mathrm{C}+850^{\circ} \mathrm{C}$; (d) $800^{\circ} \mathrm{C}+820^{\circ} \mathrm{C}$; (e) $840^{\circ} \mathrm{C}+820^{\circ} \mathrm{C}$; (f) $860^{\circ} \mathrm{C}+820^{\circ} \mathrm{C}$.

Therefore, the higher annealing temperature induces coarser grain sizes after intermediate annealing. When the grains of intermediate annealing are larger, more shear bands will be formed in the deformed microstructure after secondary cold rolling. And the distribution densities of shear bands increase as the primary recrystallization grain size increases. The recrystallization grains are preferentially nucleated at the shear bands which have higher stored energy [7]. The average grain size is enhanced with the increase of intermediate annealing temperature. Small primary recrystallization grains are conducive to the growth of secondary recrystallization grain because of the inverse relationship between primary recrystallization grain size and the driving force of the secondary recrystallization [8]. Therefore, it is important to control the primary recrystallized grain size.

3.2. Influence of Intermediate Annealing Temperature on the Primary Recrystallization Texture Distribution. Figure 3 presents EBSD orientation distribution of the primary recrystallization texture after different intermediate annealing process, in which the different colors stand for the grains with different orientations: the blue, lemon green, red purple cubic, green rotated cube, grey brass type, and brown copper type are referred to $\{111\}\langle 121\rangle$ orientation, $\{111\}\langle 110\rangle$ orientation, $\{110\}\langle 001\rangle$ orientation, $\{100\}\langle 011\rangle$ orientation, $\{110\}\langle 112\rangle$ orientation, and $\{112\}\langle 111\rangle$ orientation, respectively. Figure 4 shows the relationship between the texture content and the intermediate annealing temperature. Figure 5

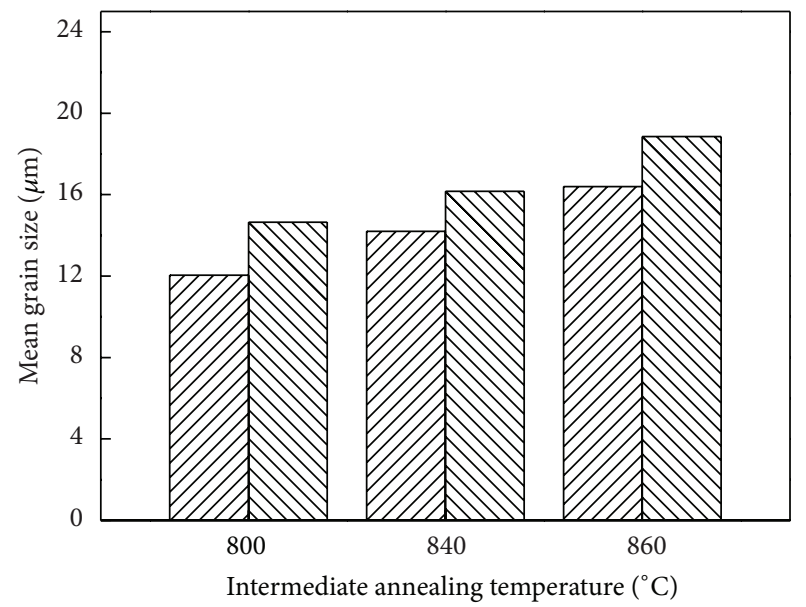

ZZ7 Primary recrystallization annealing at $820^{\circ} \mathrm{C}$ MIV Primary recrystallization annealing at $850^{\circ} \mathrm{C}$

FIGURE 2: Variations of intermediate temperature on mean grain size of primary recrystallization.

is the misorientation distribution of the primary recrystallization samples.

The current work investigated the effect of different intermediate annealing temperatures on the primary recrystallization textures under different primary recrystallization annealing temperatures which are $820^{\circ} \mathrm{C}$ and $850^{\circ} \mathrm{C}$, respectively. $\{111\}$ textures are an important texture component in primary recrystallization matrix as shown in Figure 2. 

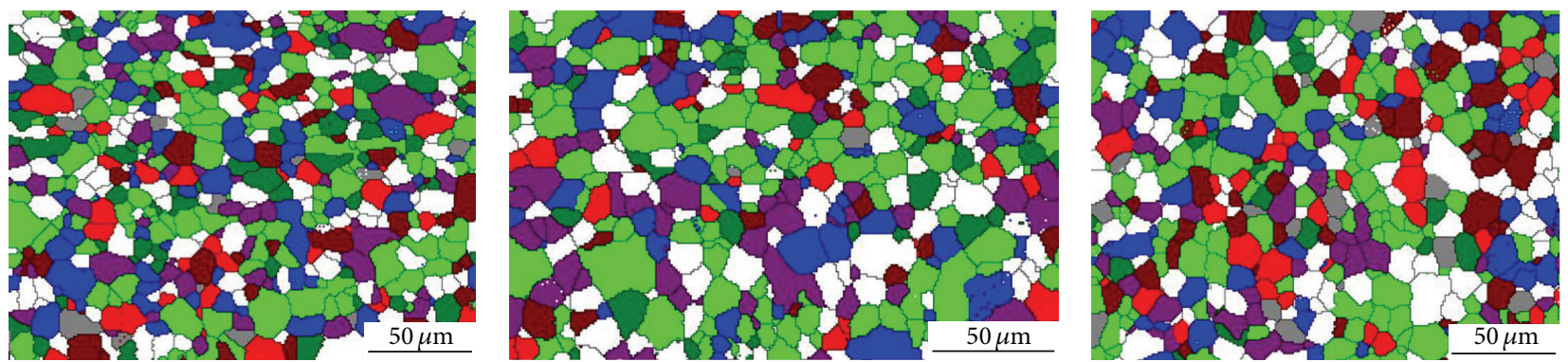

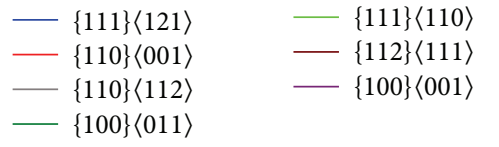

(a)

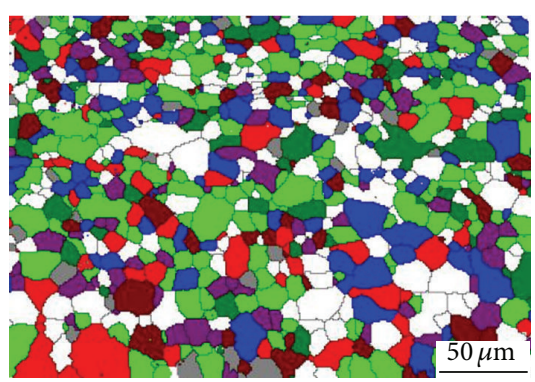

$\begin{aligned}- & \{111\}\langle 121\rangle \\ - & \{110\}\langle 001\rangle \\ - & \{110\}\langle 112\rangle \\ - & \{100\}\langle 011\rangle\end{aligned}$

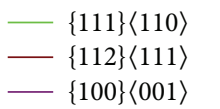

(d)
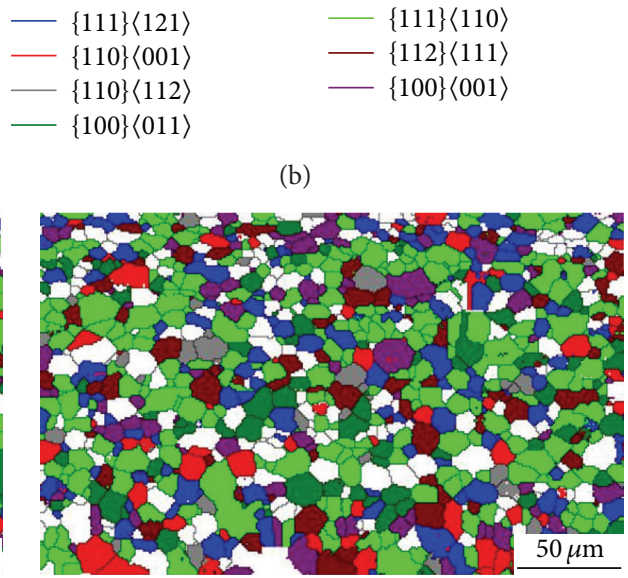
$-\{111\}\langle 121\rangle$
$-\{110\}\langle 001\rangle$
$-\{110\}\langle 112\rangle$
$-\{100\}\langle 011\rangle$

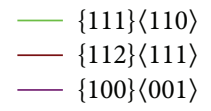

(e)

$-\{111\}\langle 110\rangle$
$-\{112\}\langle 111\rangle$
$-\{100\}\langle 001\rangle$ $-\{111\}\langle 121\rangle$

$-\{110\}\langle 001\rangle$

$-\{110\}\langle 112\rangle$

$-\{100\}\langle 011\rangle$

(c)

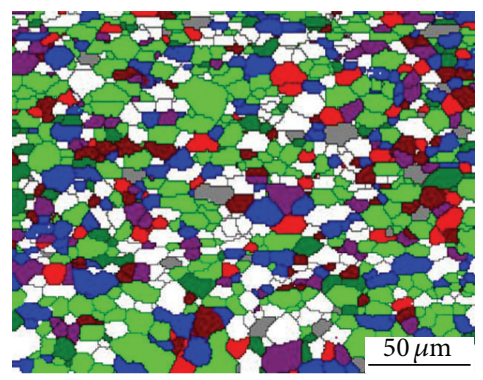

$-\{111\}\langle 121\rangle$
$-\{110\}\langle 001\rangle$
$-\{110\}\langle 112\rangle$
$-\{100\}\langle 011\rangle$

$-\{111\}\langle 110\rangle$

$-\{112\}\langle 111\rangle$

$-\{100\}\langle 001\rangle$

(f)

FIGURE 3: Grain orientation mapping of tested samples under different intermediate temperatures during primary recrystallization: (a) $800^{\circ} \mathrm{C}+850^{\circ} \mathrm{C}$; (b) $840^{\circ} \mathrm{C}+850^{\circ} \mathrm{C}$; (c) $860^{\circ} \mathrm{C}+850^{\circ} \mathrm{C}$; (d) $800^{\circ} \mathrm{C}+820^{\circ} \mathrm{C}$; (e) $840^{\circ} \mathrm{C}+820^{\circ} \mathrm{C}$; (f) $860^{\circ} \mathrm{C}+820^{\circ} \mathrm{C}$.

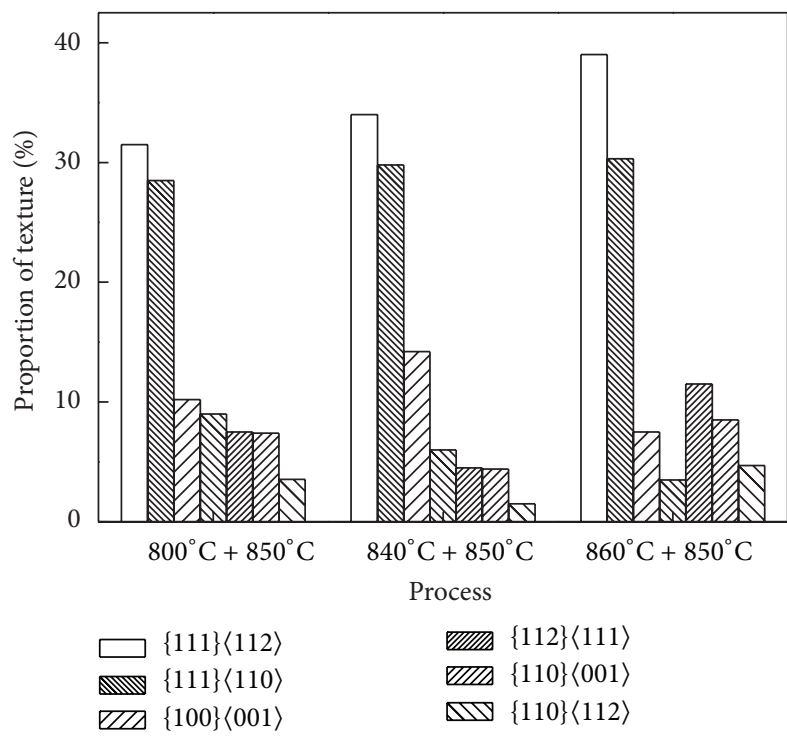

(a)

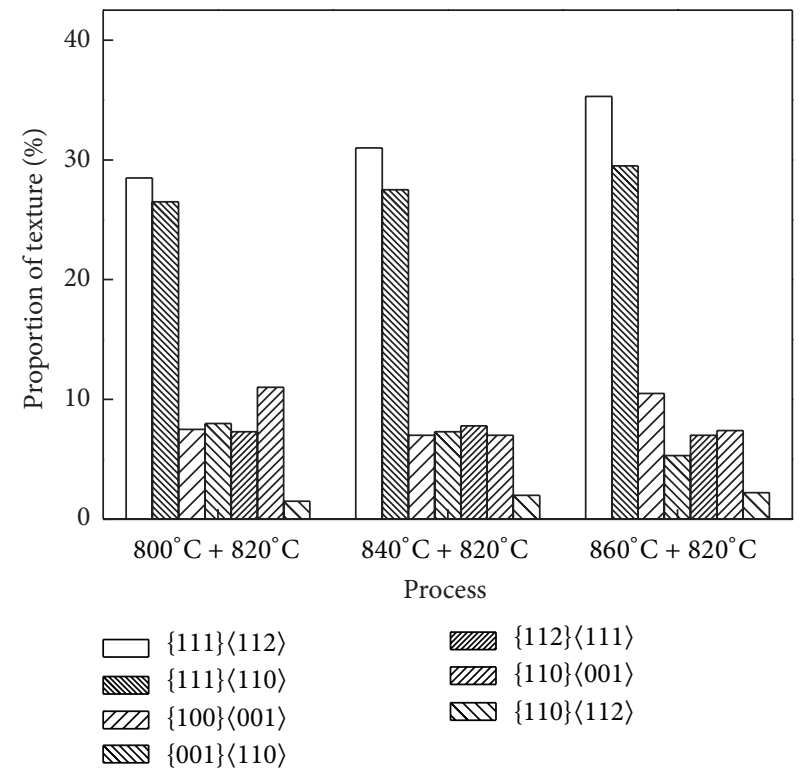

(b)

FIGURE 4: Proportions of typical textures in primary recrystallization samples under different intermediate annealing processes: (a) test group of samples intermediately annealed at $850^{\circ} \mathrm{C}$; (b) test group of samples intermediately annealed at $820^{\circ} \mathrm{C}$. 


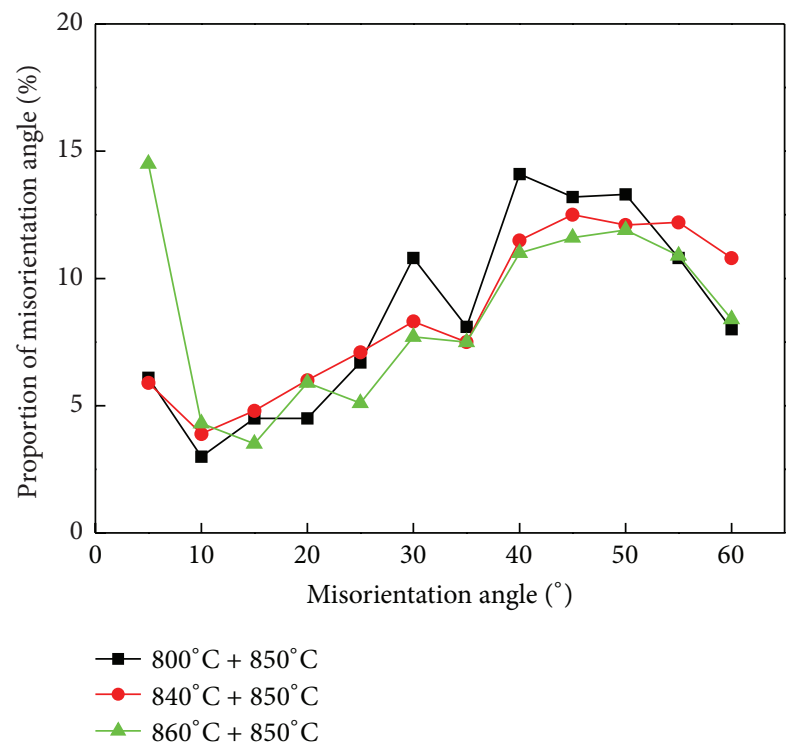

(a)

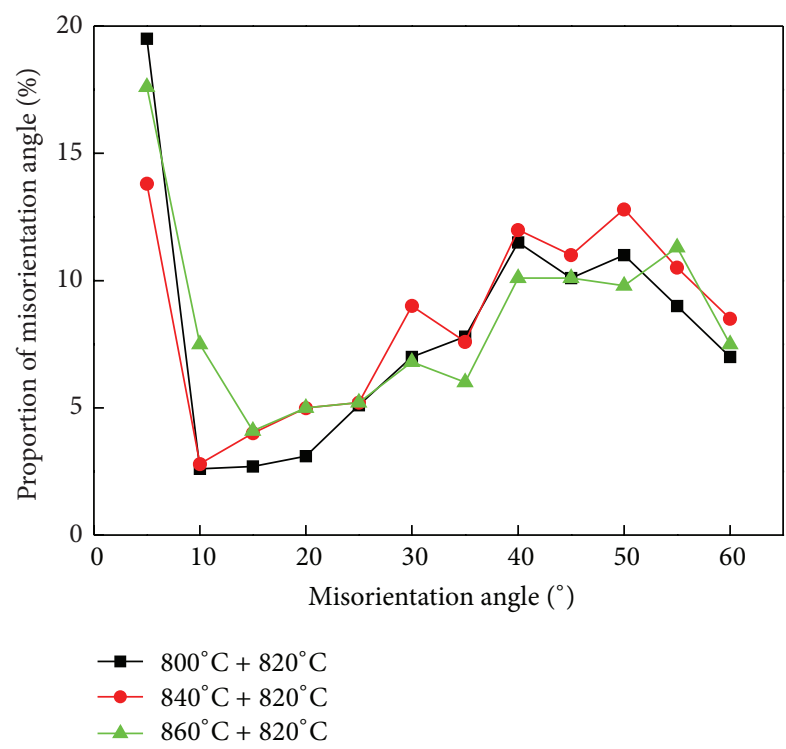

(b)

FIGURE 5: Misorientation distribution under different intermediate annealing temperatures: (a) test group of samples intermediately annealed at $850^{\circ} \mathrm{C}$; (b) test group of samples intermediately annealed at $820^{\circ} \mathrm{C}$.

$\{111\}\langle 121\rangle$ texture and $\{111\}\langle 110\rangle$ texture are important $\{111\}$ fiber textures, and the content of $\{111\}\langle 121\rangle$ texture is slightly higher than that of $\{111\}\langle 110\rangle$ texture in this study. The contents of both $\{111\}\langle 121\rangle$ texture and $\{111\}\langle 110\rangle$ texture are increased when the intermediate annealing temperature is raised from $800^{\circ} \mathrm{C}$ to $860^{\circ} \mathrm{C}$ in the condition of the primary recrystallization temperature of $820^{\circ} \mathrm{C}$ as shown in Figure 5(a). The same phenomenon can also be observed in Figure 4(b). This means that the increase of intermediate annealing temperature is a benefit to obtain a higher strength of $\gamma$ fiber texture. There are two theories to explain the formation of the annealing texture in CGO silicon steel. One is the preferential nucleation theory and the other is the preferential growth theory [9]. The primary recrystallization texture of CGO silicon steel is related to the preferential nucleation of new grains with certain orientation in deformed matrix. In the recrystallization process of CGO silicon steel, the undistorted grains are generated in the matrix gradually by absorbing the deformed matrix, and the deformation energy is released, which is the driving force of recrystallization. The deformation energies of different oriented grains are ordered by $\{110\}>\{111\}>\{112\}>$ $\{001\}$. The stored energy of $\{110\}$ grains is higher than the $\{111\}$ grains, so the recrystallization of $\{110\}$ oriented grains is generated by consuming $\{111\}\langle 121\rangle$ oriented grains, which makes the Goss texture intensity increased. When the primary recrystallization annealing temperature is $850^{\circ} \mathrm{C}$, the content of Goss texture decreases from $7.92 \%$ to $4.38 \%$ and then increases to $8.52 \%$ with the increase of intermediate annealing temperature as presented in Figure 4. The phenomenon that the content of Goss texture decreases at first and then increases can also be observed in the condition of $820^{\circ} \mathrm{C}$ annealing temperature. This indicates that the grains with Goss orientation start to grow in the primary recrystallization matrix and its growth rate is faster in a higher intermediate annealing temperature. The increase of the Goss grains in primary recrystallization matrix is a benefit to the abnormal growth of Goss oriented grains during secondary recrystallization $[10,11]$. Multiple and concentrate $\{111\}\langle 121\rangle$ texture and proper amount of $\{110\}\langle 001\rangle$ texture with accurate orientation in the primary recrystallization matrix are necessary conditions for CGO silicon steel to gain excellent magnetic properties.

$\{111\}\langle 121\rangle$ texture formed in the primary recrystallization is an important texture component of CGO silicon steel, which is always located near the grains with $\{110\}\langle 001\rangle$ orientation. The misorientation between $\{111\}\langle 121\rangle$ and $\{110\}\langle 001\rangle$ textures is 35.3 degrees, which is a high energy boundary with high angle, improves the boundary mobility of $\{110\}\langle 001\rangle$ oriented grains, and is conducive to the abnormal growth of Goss grains in the secondary recrystallization process [12]. Figure 5(a) shows that the misorientation distributions of specimens after different annealing process are mainly high energy grain boundaries (misorientations between $20^{\circ}$ and $45^{\circ}$ ). The specimen that experienced the annealing of $840^{\circ} \mathrm{C}+850^{\circ} \mathrm{C}$ has the most content of high angle boundaries compared with other processes, and the specimen that experienced the annealing of $860^{\circ} \mathrm{C}+850^{\circ} \mathrm{C}$ has the most content of low angle boundaries. Figure 5(b) shows that the content of the high angle boundaries of the specimen with annealing of $840^{\circ} \mathrm{C}+820^{\circ} \mathrm{C}$ is slightly higher than that of the other processes, and the contents of low angle boundaries are similar among these processes. A large number of high angle boundaries are conducive to improving the mobility of the boundaries. Moreover, the unstable microstructure is beneficial to the abnormal growth of Goss grains during the secondary recrystallization [13]. As presented in Figures 5(a) and 5(b), a higher primary 
recrystallization annealing temperature can reduce the content of low angle boundaries and increase the content of high angle boundaries at the same intermediate annealing temperature, which is conducive to the abnormal growth of Goss grains during the secondary recrystallization [10].

\section{Conclusions}

(1) CGO silicon steel went through intermediate annealing at $800^{\circ} \mathrm{C}, 840^{\circ} \mathrm{C}$, and $860^{\circ} \mathrm{C}$; then, primary recrystallization at $820^{\circ} \mathrm{C}$ and $850^{\circ} \mathrm{C}$ obtained equiaxed ferrite microstructure in the experimental specimens. The average grain size after primary recrystallization annealing is increased with the rising of intermediate annealing temperature.

(2) The primary recrystallization texture of CGO silicon steel is affected by the intermediate annealing temperature. The contents of $\{111\}\langle 121\rangle$ texture and $\{111\}\langle 110\rangle$ texture in $\gamma$ fiber are gradually increased, and the content of $\{111\}\langle 121\rangle$ texture is slightly higher than that of $\{111\}\langle 110\rangle$ texture. $\{111\}\langle 121\rangle$ texture can be transformed into Goss $\{110\}\langle 001\rangle$ texture. Goss texture in primary recrystallization matrix decreases first and then increases with the rising of intermediate annealing temperature.

(3) The content of high angle boundaries after primary recrystallization is influenced by the intermediate annealing temperature of CGO silicon steel, which is increased at first and then decreased with the rising of intermediate annealing temperature. Misorientation distributions are also influenced by the primary recrystallization temperature. A higher primary recrystallization temperature is conducive to reducing the content of low angle boundaries and increasing that of high angle boundaries, provided favorable conditions for the abnormal growth of Goss grains exist.

\section{Competing Interests}

The authors declare that they have no competing interests.

\section{Acknowledgments}

The authors acknowledge the Fundamental Research Funds for the Central Universities (TP-A3) for their financial support.

\section{References}

[1] X. Miao, Y. H. Wei, W. K. Zhang et al., "Effect of intermediate annealing temperature between double cold reduction on structure and performance of $2.3 \mathrm{Si}$ non-oriented silicon steel," Special Steel, vol. 35, no. 2, pp. 57-59, 2014.

[2] F. Ju, Z. Jin, H. Ren, K. Sun, and W. Qu, "Effects of secondary cold-rolled intermediate annealing on microstructure and texture of grain-oriented silicon steel based on CSP technology," Heat Treatment of Metals, vol. 39, no. 6, pp. 64-67, 2014.

[3] L. Liu, P. Yang, J. Qin et al., "Effects of rolling reduction and intermediate annealing on the microstructure and texture of $6.5 \mathrm{wt} \%$ Si electric steel during warm rolling," Journal of Chinese Electron Microscopy Society, vol. 32, no. 6, pp. 459-466, 2013.
[4] Y. G. Chen, L. F. Fan, C. Zhang et al., "Determination of intermediate complete decarburizing annealing process of common grain-oriented silicon steel," Materials for Mechanical Engineering, no. 11, pp. 73-76, 2013.

[5] J. Jia, W. Zhu, L. Dai et al., "Analysis of the characteristics of grains and grain boundaries in the non-oriented steel by EBSD," Journal of Wuhan University of Science and Technology, vol. 32, no. 5, pp. 491-495, 2009.

[6] W. X. Song, Metallurgy, Metallurgical Industry Press, 1980.

[7] Z. Xue, "Effect of normalizing temperature of hot rolled plate on structure and properties of 3.0 Si non-oriented electric steel," Special Steel, vol. 29, no. 6, pp. 58-60, 2008.

[8] T.-L. Dong, X. Li, E.-B. Yue, S.-T. Qiu, and P. Zhao, "Microstructure development of grain oriented silicon steel produced by thin slab casting and rolling process," Journal of Iron and Steel Research, vol. 22, no. 7, pp. 56-58, 2010.

[9] J. Harase, R. Shimizu, and D. J. Dingley, “Texture evolution in the presence of precipitates in Fe-3\% Si alloy," Acta Metallurgica Et Materialia, vol. 39, no. 5, pp. 763-770, 1991.

[10] L.-B. Zhang, Z.-L. Jin, L. Lan, L.-J. Li, X.-M. Cao, and R.-T. Cui, "Grain boundary characteristics of primary recrystallization for the impact of the macro-texture based on CSP technology," Transactions of Materials and Heat Treatment, vol. 34, no. 1, pp. 97-101, 2013.

[11] Z. Li, N. Dang, D. Tang, Z. Mi, and D. Fan, “Texture evolution of CGO silicon steel during primary recrystallization process under wet hydrogen atmosphere," Heat Treatment of Metals, vol. 37, no. 12, pp. 1-5, 2012.

[12] J.-X. Yang, J. Liu, S.-D. Li, C.-Y. Li, and R.-P. Wang, "Influence of preliminary annealing temperature on primary recrystallization texture of high permeability grain-oriented silicon steel," Transactions of Materials and Heat Treatment, vol. 34, no. 3, pp. 114-117, 2013.

[13] J.-J. Geng, H. Yu, and Y.-F. Fan, "Effect of normalizing temperature on texture and magnetic property of hot-rolled nonoriented silicon steel," Transactions of Materials and Heat Treatment, vol. 34, no. 1, pp. 93-96, 2013. 

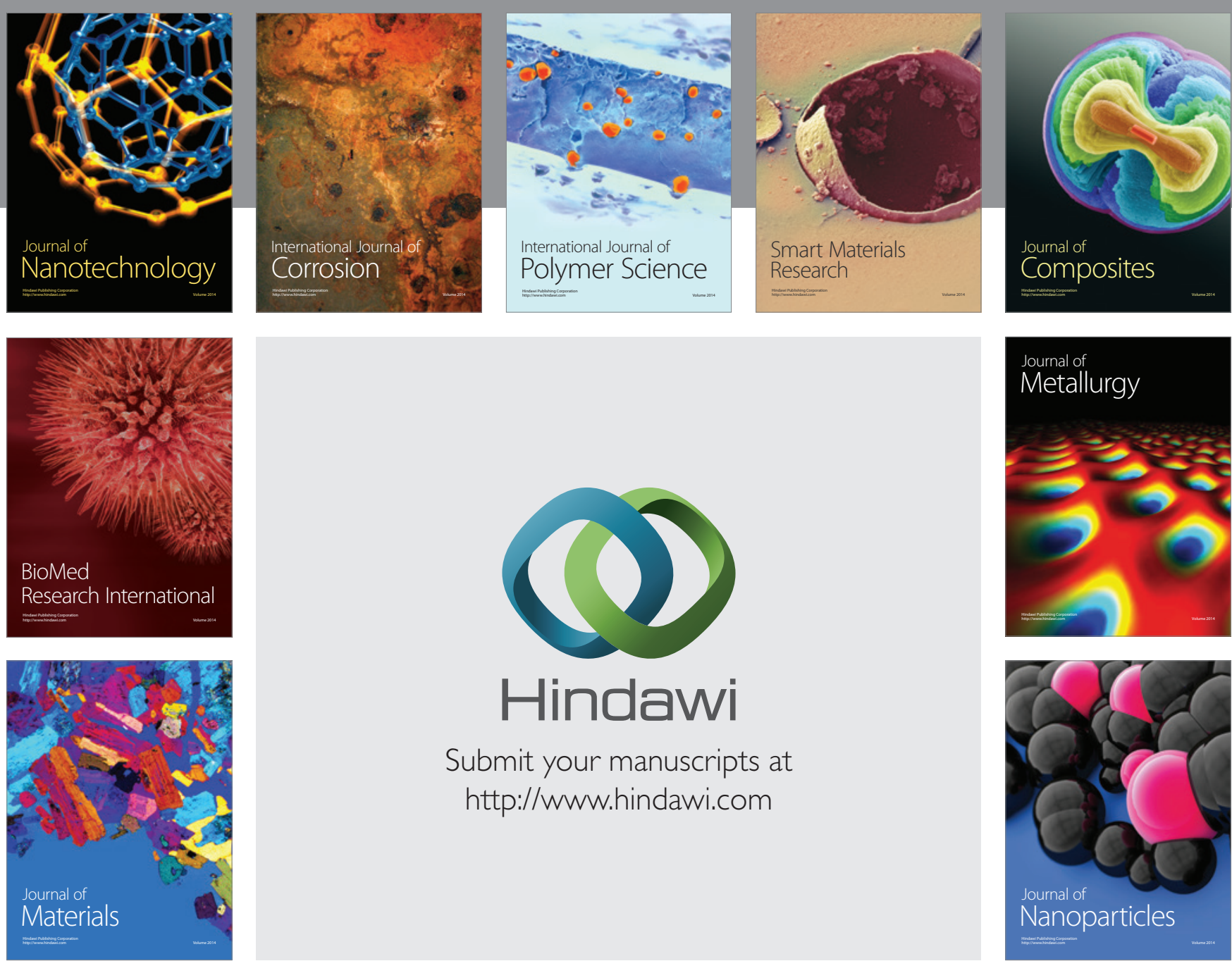

\section{Hindawi}

Submit your manuscripts at

http://www.hindawi.com

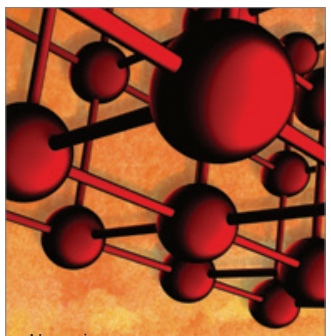

Materials Science and Engineering
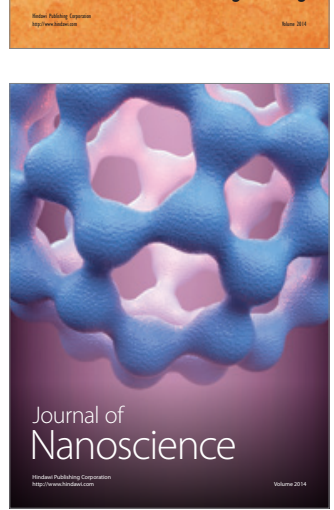
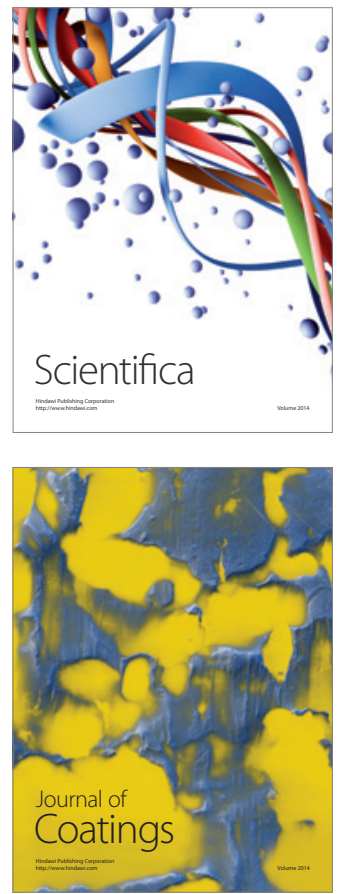
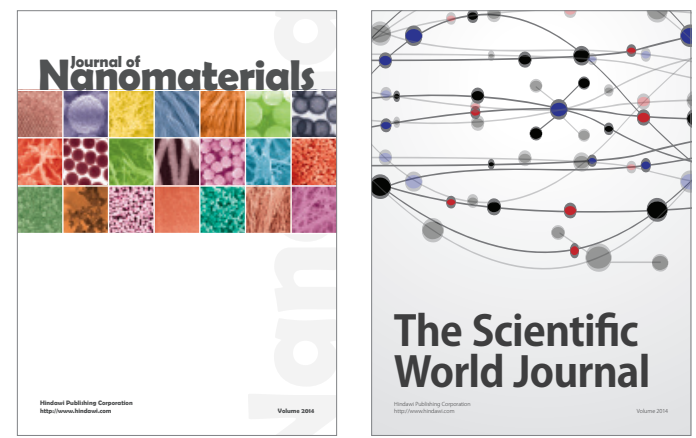

The Scientific World Journal
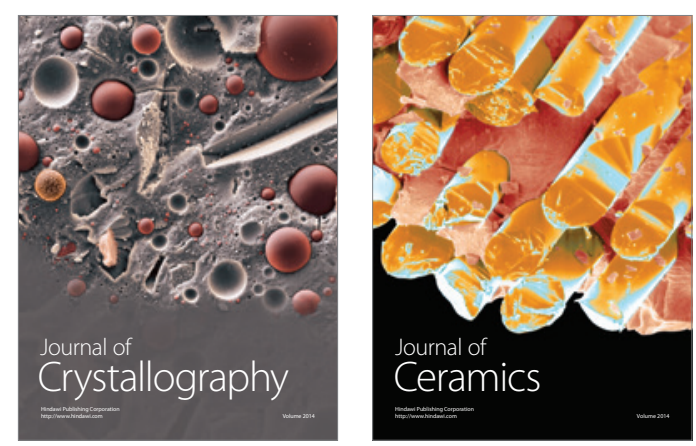
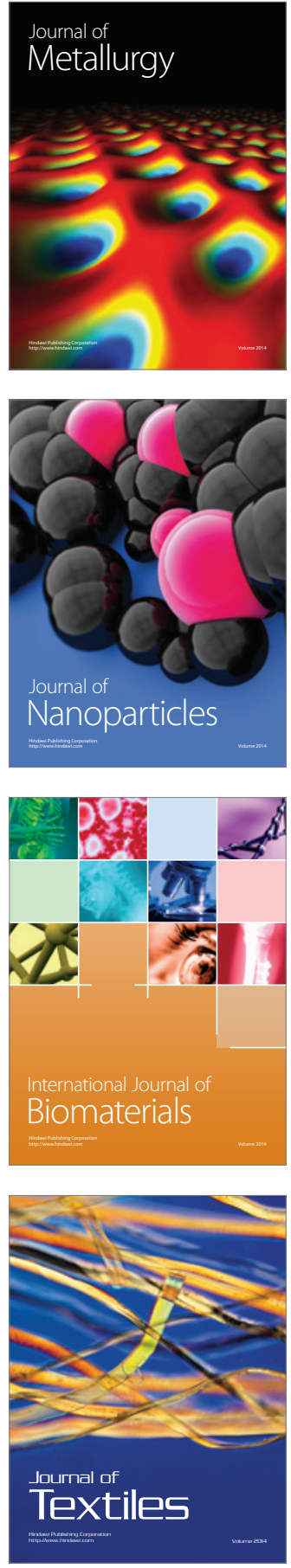